\title{
Vietnamese migrants are as tall as they want to be
}

\author{
Christiane Scheffler ${ }^{1}[1] \cdot$ Thi Hong Nguyen $^{1} \cdot$ Michael Hermanussen $^{2}$ () \\ 1 University of Potsdam, Institute of Biochemistry and Biology, Human Biology, Am Neuen Palais 10, 14467 Potsdam, Germany \\ ${ }^{2}$ Aschauhof, 24340 Eckernförde-Altenhof, Germany
}

\section{Citation:}

Scheffler, C, Nguyen, T, Hermanussen, M ( 2021 ) Vietnamese migrants are as tall as they want to be, Human Biology and Public Health 2.

https://doi.org/10.52905/hbph.v2.12.

Received: 2021-03-02

Accepted: 2021-05-25

Published: 2021-12-22

\section{Copyright:}

This is an open access article distributed under the terms of the Creative Commons Attribution License which permits unrestricted use, distribution, and reproduction in any medium, provided the original author and source are credited.

\section{Conflict of Interest:}

There are no conflicts of interest.

\section{Correspondence to:}

Christiane Scheffler

email: christiane.scheffler@uni-potsdam.de

\section{Keywords:}

body height, regulation of growth, migrants, SocialEconomic-Political-Emotional (SEPE) factors

\begin{abstract}
Background Members of the same social group tent to have the same body height. Migrants tend to adjust in height to their host communities.

Objectives Social-Economic-Political-Emotional (SEPE) factors influence growth. We hypothesized that Vietnamese young adult migrants in Germany (1) are taller than their parents, (2) are as tall as their German peers, and (3) are as tall as predicted by height expectation at age 13 years.

Sample The study was conducted in 30 male and 54 female Vietnamese migrants (mean age 26.23 years. $\mathrm{SD}=4.96$ ) in Germany in 2020.

Methods Information on age, sex, body height, school and education, job, height and ethnicity of best friend, migration history and cultural identification, parental height and education, and recalled information on their personal height expectations at age 13 years were obtained by questionnaire. The data were analyzed by St. Nicolas House Analysis (SNHA) and multiple regression.

Results Vietnamese young adults are taller than their parents (females $3.85 \mathrm{~cm}$, males $7.44 \mathrm{~cm}$ ), but do not fully attain height of their German peers. The body height is positively associated with the height of best friend $(\mathrm{p}<0.001)$, the height expectation at age 13 year $(\mathrm{p}<0.001)$, and father's height $(\mathrm{p}=0.001)$.

Conclusion Body height of Vietnamese migrants in Germany reflects competitive growth and strategic growth adjustments. The magnitude of this intergenerational trend supports the concept that human growth depends on SEPE factors.
\end{abstract}

Take home message for students Migrants adjust in body height towards the height of their peers and reflect competitive growth and strategic growth adjustments. Growth adjustments reflect the emotional challenge during the process of integration towards future social position within the host society. The magnitude of intergenerational trends supports that growth depends on Social-Economic-PoliticalEmotional (SEPE) factors. 


\section{Introduction}

Human body height varies considerably. Average height of modern populations varies by up to $30 \mathrm{~cm}$, average body height of the same population may vary by up to $20 \mathrm{~cm}$ within time periods of only 100 years (NCD Risk Factor Collaboration 2016). The variability of human height and its dependence on Social-EconomicPolitical-Emotional (SEPE) factors (Bogin 2021a) is particularly evident in people who move from one place of residence to another, especially from their place of birth to a geographically and socially new place of residence (migrants) (Bogin et al. 2018). Integrating into the local social networks is often difficult and prejudice against the newcomers may lead to ethnic conflicts (Landis and Alber 2012), but most migrants tend to assimilate in the new community. The transition can produce behavioral and psychological responses, as well as physical changes in the amount and tempo of child growth and attained adult height (MascieTaylor and Krzyżanowska 2017; Bogin et al. 2018).

Migrants assimilate not only in height. Already 100 years ago, Boas (1912) observed the plasticity of human cranial form in US immigrants, challenging traditional doctrines of hereditary, so-called 'racial', characteristics in the human form. Boas found parallel changes in body height, and discussed various possible causes including nutrition, but eventually failed to provide convincing explanations.

In contrast to the variability of body height between different populations and within the same population throughout history, the variability of body height is comparably small when considering social and ethnic groups living at the same historic time and in the same geographic location. People whose places of residence are close to each other are similar in height. Aß- mann and Hermanussen (Aßmann and Hermanussen 2013) called this the "community effect in body height". The community effect in body height describes the "effect of social interaction within a group on the growth and body height of its members" (Hermanussen and Scheffler 2019). Newcomers tend to adjust in height to their host communities (Laor et al. 1991; Bogin and Loucky 1997; Bogin et al. 2002).

Body height relates to social position. Tall persons tend to be dominant (Marsh et al. 2009), and are preferentially found among upper social classes. As humans only grow during a certain number of years and reach final height at early adulthood, the time for social growth adjustments is limited. Anticipating future social positions is difficult. Thus, strategic growth adjustments is considered a probabilistic assessment at the group level. Members of the same social groups/strata are aware of their social strata, and collectively generate appropriate lifelong signals of their putative future positions. Thus, adult height may be considered the "frozen perception" of an adolescent's idea of his or her future position within the social network. Perceived dominance tends to adjust height towards tall targets and results in growth stimulation (stature signals status). The prospect of a later dominant social position stimulates growth (Hermanussen and Scheffler 2016). Nearly 100,000 people live in Germany with a migration background from Vietnam (Statista 2021). Most of them had arrived in the former GDR and still stay with their families all over Germany. Their children went to German schools, and most of the second generation has already reached adult age. In view of the SEPE factors that had shaped their socialization, we developed the following hypotheses: 
1. Vietnamese young adults are taller than their parents.

2. Vietnamese young adults are as tall as their German peers.

3. Body height of Vietnamese adults is predicted by height expectation at age 13 years.

\section{Sample and Methods}

\section{Sample}

The study was conducted in 84 (30 males, 54 females) Vietnamese migrants aged between 17 and 40 (mean=26.23 years. $\mathrm{SD}=4.96$ ). Two participants belonged to the $3^{\text {rd }}, 56$ participants to the $2^{\text {nd }}$ and 26 participants to the $1^{\text {st }}$ generation of migrants. Five participants were older than 13 years upon arrival in Germany. All participants went to school in Germany.

\section{Data collection}

Participation was voluntary, all data were collected anonymously by electronic questionnaire system LamaPoll (2021). Snowball sampling was applied for recruitment. Criteria for inclusion was: both parents originated from Vietnam.

We asked for age, sex and recent body height, education and recent job, percentage of migrant children in nursery school, primary, and secondary school, as well as the body height and ethnicity of best friend, cultural identification to German and Vietnamese culture including nutritional behavior. Information about the migration history (generation or age of migration of participants, parents' age of migration, age of the migration request), body height and education of father and mother were included. We explicitly asked to recall their personal expectations at age 13 years. We inquired how tall they wanted to become when adult, and about their preferred future job.

The questionnaire included nominal and interval scales on the perceived belongingness to either the Vietnamese or the German culture. Information on preferred and on actual job was ranked according to "social acceptance". Social acceptance of the various professions was derived from a separate questionnaire given to a group of Vietnamese migrants who were asked to rank the professions mentioned.

\section{Statistics}

Body height was converted to standard-deviation-scores (hSDS) according to WHO reference (Growth reference data for 5-19 years 2021).

After calculating all possible bivariate correlations, we performed a primary data exploration with St. Nicolas House Analysis (SNHA) (Groth et al. 2019; Hermanussen et al. 2021). This new statistical method is a robust non-parametric statistical tool for immediate visualization of essential associations between extensive interacting variables. Bivariate correlation coefficients are ranked in descending order according to magnitude thereby creating hierarchic "association chains". Association chains are used to characterize dependence structures of interacting variables. Association chains are depicted by a graph. Overlapping association chains create network graphs. SNHA offers an initial foundation that was used for the subsequent hypothesis-driven testing.

Variables that could not be assigned to association chains were stepwise excluded from the data set. We then eliminated the variable body height from the reduced data set, and performed a linear regression to separately estimate the influence of these variables on body height. 
All analyses were done using the program R (version 3.5.1) (R Core Team 2018).

\section{Results}

Young adult Vietnamese migrants in Germany are significantly taller than their parents. Within one generation girls increased by $3.85 \mathrm{~cm}$ compared with their mothers, boys are $7.44 \mathrm{~cm}$ taller than their fathers (Table 1), and thus, almost halved the height gap between parental height and height of young German adults. Vietnamese adolescents want to be taller than their parents. When explicitly asked to recall their personal expectation at age 13 years how tall they wanted to become when adult (wish at 13 years), they mentioned body heights close to current references for young German adults (Table 1).

Twenty-one variables were obtained by the questionnaire. Figure 1a illustrates the extensive interaction of these variables. In order to better highlight the complex network of these interactions, we performed a St. Nicolas House Analysis (SNHA). SNHA signalized a mixture of clustered and isolated variables (Figure 1b). After eliminating isolated variables (Figure 1c), four clusters remained (Figure 1d). Variables reflecting the migration history of the parents and the cultural identity (migration age of mother and father, age of migration, generation of migrants, ties to German culture, desire to preserve Vietnamese culture) formed one independent cluster (migration cluster). Parental education and the desire to adopt the German culture formed the second independent cluster (cultural cluster). The third cluster was formed by factors related to early socialization (percentage of migrants in nursery and in primary school) (socialization cluster). The fourth independent cluster incorporates variables related to body height (body height of father, body height of mother, body height of the best friend, the personal expectation of height at 13 yrs) (body height cluster). In contrast to the clusters 1-3 that are serially arranged, the body height cluster is radially arranged with hSDS of the participant in the central position. Information related to nutrition, ethnicity, personal education, and ideas about one's future job, and the number of migrants in the secondary school did not serially associate with other variables. SNHA clarified the correlation structure of the different variables and particularly highlighted the exclusive influence on body height of the social core group, i.e. height of friends and parents, and the importance of the desired future physical appearance at mid-adolescence.

Table 1 Mean and SD of body height (cm) and hSDS (WHO- reference) of adult Vietnamese migrants (age 17-40 years, mean=26.23, $S D=4.96$ ) and recalled personal expectation of adult height at age 13 (wish at 13 years). Parental height, SD of height, and hSDS, and height and SD of height (cm) of 17-year-old German girls and boys (KiGGS data (Robert-Koch-Institut 2021).

\begin{tabular}{|c|c|c|c|c|c|c|c|c|}
\hline & \multicolumn{5}{|c|}{ Female } \\
\hline & height & SD & hSDS & SD & height & SD & hSDS & SD \\
\hline adult & 160.70 & 6.02 & 0.37 & 0.92 & 173.07 & 6.48 & -0.48 & 0.89 \\
\hline wish at 13 years & 165.79 & 5.50 & 0.39 & 0.84 & 177.02 & 7.27 & 0.15 & 0.96 \\
\hline mother & 156.85 & 4.41 & -0.96 & 0.67 & 156.97 & 4.67 & -0.95 & 0.71 \\
\hline father & 166.80 & 7.83 & -1.33 & 1.07 & 165.63 & 4.83 & -1.49 & 0.66 \\
\hline KiGGS data & 165.37 & 6.56 & & & 178.06 & 6.56 & & \\
\hline
\end{tabular}




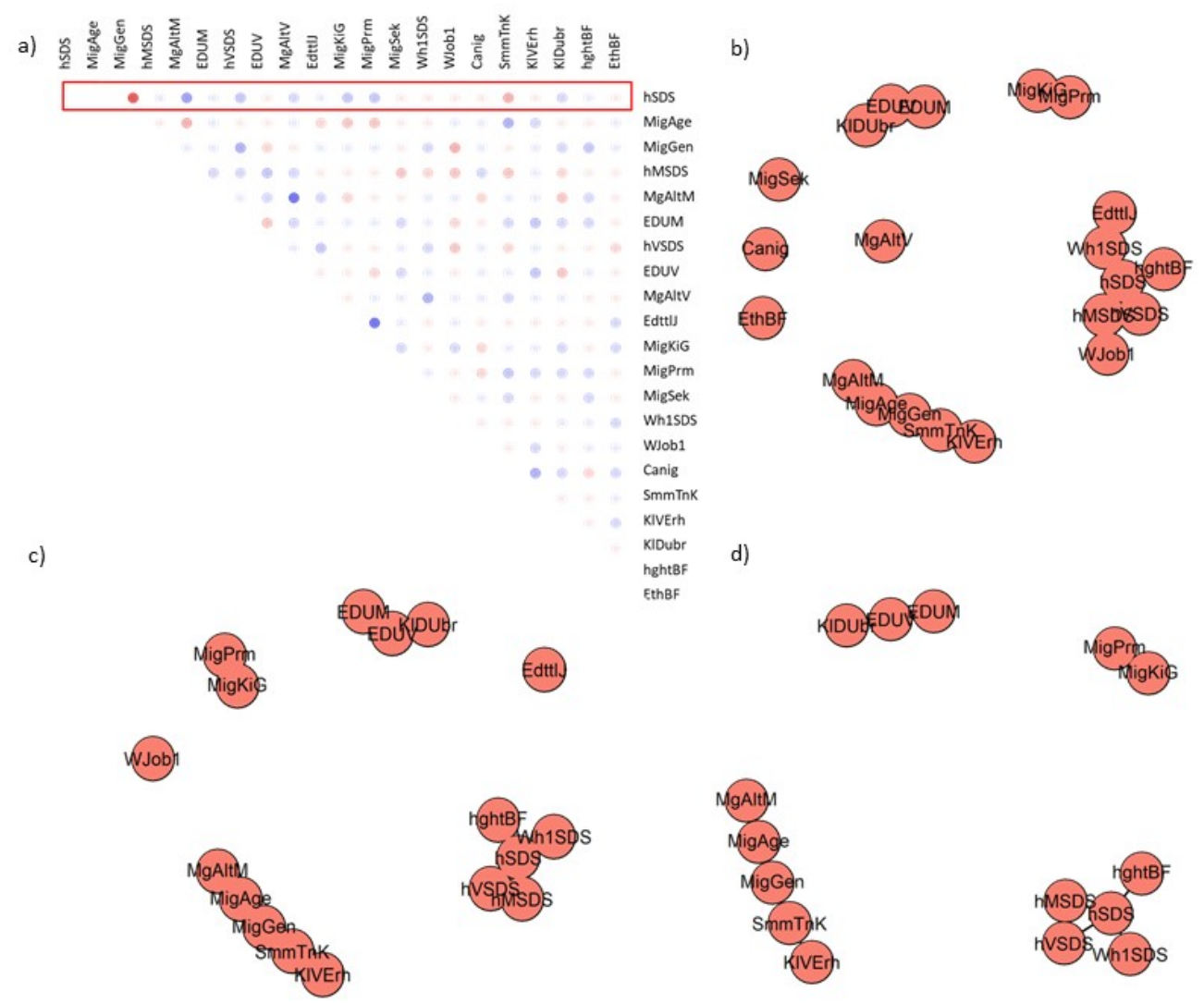

Figure 1 Correlation matrix (a) of 21 obtained variables by the questionnaire and St. Nicolas plots (alpha 0.01): b) plot with all variables; c) plot after reduction of no associated variables from plot a; d) plot after reduction of no associated variables from plot b. (hSDS - body height of test person, Canig - meat consumption in g, EDUF-education father, EDUM - education mother, EdttIJ - education of test person in total years, EthBF- ethnicity of best friend, hVSDS - body height of father, hMSDS - body height of mother, hghtBF - body height of the best friend, KIDubr-desire to adopt German culture, KIVErh- desire to preserve Vietnamese culture, MigPm - percentage of migrants in primary school, MigkiG percentage of migrants in nursery, MigSek-percentage of migrants in secondary school, MigAltVmigration age of father, MgAltM- migration age of mother, MigAge- age of migration , MigGen-generation of migrants, SmmTnK- ties to German culture, Wh1SDS - the wish of height at 13 yrs, WJob1 - job wish at an age of 13 years).

In order to further analyze the associative structure of the height related variables we implemented a multiple regression to quantify the influence on adult height (Table 2, Figure 2).

Body height of Vietnamese adults was influenced by circumstances and expectations at mid-puberty. Figure 2 depicts the association between adult height (hSDS) and body height of the best friend, height (hSDS) expectations at age 13 years, and paternal height (hSDS). Table 2 quantifies these influences by multiple regression analysis. Body height of the mother appeared to be of less importance.

\section{Discussion}

Body height of young adult Vietnamese migrants raised and living in Germany is influenced by body height of the people they live closest with in the same community.

Young Vietnamese adults are taller than their parents supporting our first hypothesis. With a secular trend of $7.44 \mathrm{~cm}$ in males 
a)

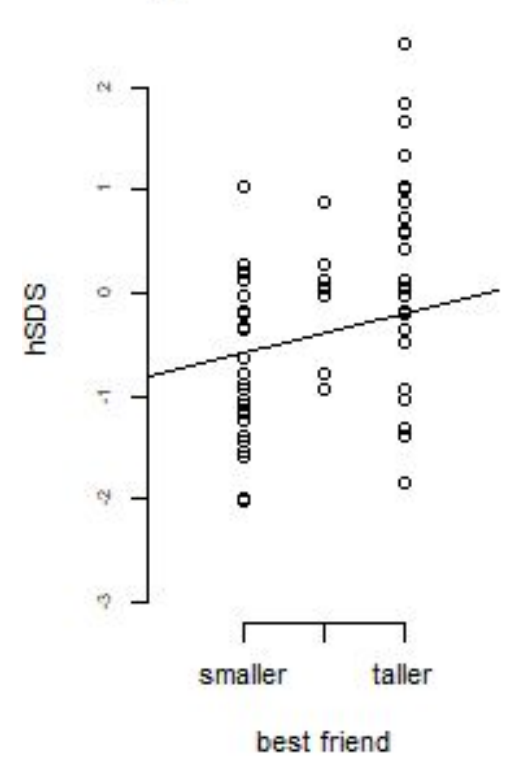

b)

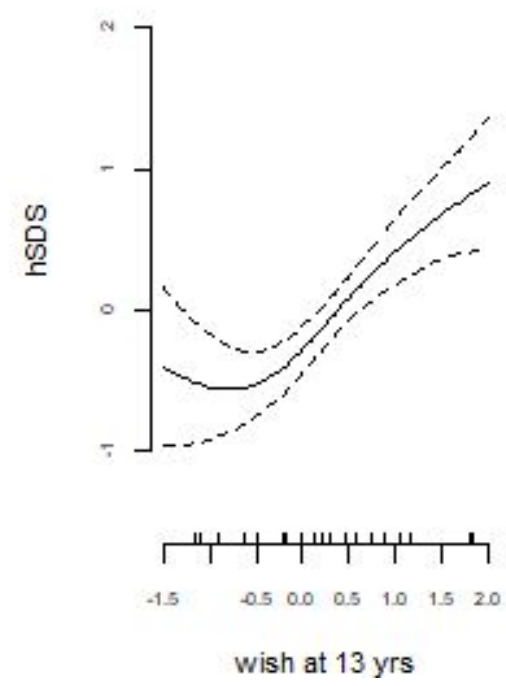

c)

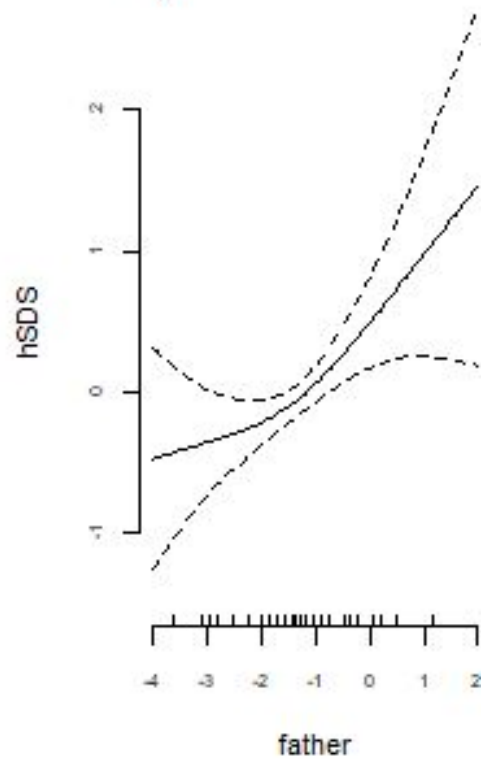

Figure 2 Body height (hSDS) of adult Vietnamese migrants in Germany depending on a) body height of best friend, $p<0.001$, b) body height $S D$ expectation at age of 13 years $p<0.001$, c) the body height $S D$ of the father, $p=0.001$. Multiple regression (adj. $R^{2}=0.415$, $F=15.71$ on 4 and 79 DF). Dotted lines indicate confidence intervals (95\%).

and $3.85 \mathrm{~cm}$ in females this intergenerational difference is high and in the males outranges the average trend of some $2 \mathrm{~mm}$ per year documented by the NCD Risk Factor Collaboration (2016). The trend in the migrant Vietnamese boys almost doubles the trend in male height of $4 \mathrm{~cm}$ observed in Vietnam between 1985 and 2019. In spite of the marked intergenerational increase in body height in boys and girls, Vietnamese migrants in Germany are still some $5 \mathrm{~cm}$ shorter than their German peers. We thus partially rejected our second hypotheses. The present study highlights the influence of the peers on body height. Whereas the ethnicity of the best friend is not associated with body height, height of the best friend is. Body height of the peer group matters. Height expectations of migrant Vietnamese at age 13 years are very close to that of German adolescents (Table 1). So we have to accept our third hypothesis: body height of Vietnamese adults is predicted by height expectations at age 13 years. The taller a mid-pubertal Vietnamese adolescent wants to be as an adult, the taller he and she grows (Figure $2 b$ ). The present study challenges the concept of major genetic influence on body height and rather supports recent estimates that

Table 2 Degree of influence on adult height of the variables of the body height cluster. Parental height (hSDS mother, hSDS father), the expectation of the future adult height at an age of 13 years (hSDS wish at 13yrs.), and the body height of the best friend (height best friend). Multiple regression (adj. $R^{2}=0.415, F=15.71$ on 4 and 79 DF, $p$-value: $<0.001^{\star * *}$ ). $C l=$ confidence interval.

\begin{tabular}{|c|c|c|c|}
\hline & & Cl (95\%) & $P$ \\
\hline (intercept) & -0.789 & $-1.258,-0.319$ & $0.001^{* *}$ \\
\hline hSDS father & 0.198 & $0.027,0.369$ & $0.024^{*}$ \\
\hline hSDS mother & 0.123 & $-0.123,0.37$ & 0.323 \\
\hline hSDS wish at 13 yrs. & 0.359 & $0.184,0.533$ & $<0.001^{* * *}$ \\
\hline height best friend & 0.385 & $0.213,0.557$ & $<0.001^{* * *}$ \\
\hline
\end{tabular}


the genetic impact on height only ranges between 12.3\% (Tyrrell et al. 2016) and 27.4\% (Marouli et al. 2017). The marked association between achieved adult height, adolescent height expectations, and height of best friends supports the view that SEPE factors significantly interfere in the regulation of human growth (Bogin 2021a; 2021b).

The significant association between achieved body height and paternal (Figure 2c), but not maternal, height further underscores the role of social rather than genetic factors in the regulation of growth and final height. The family forms the core of Southeast Asian and Chinese culture, and the strong patriarchal structures characterized by hierarchical role obligations shapes the social network within which the child and adolescent develops. It has been shown that this socio-cultural picture tends to persist in Vietnamese migrant families living in Germany (Stephan 2000).

Nevertheless, migrants do significantly change conditions and slowly adapt within the social, economic and political background of their hosts. This is an enormous emotional challenge. Vietnamese migrants face this challenge. Besides the cultural (acquisition of knowledge and skills), the structural (degree of education, working place), and the social dimension (social relationship) (Esser 2016), the emotional challenge includes emotional integration and identification in the sense of a personal sense of belonging to community. Belonging to a particular community influences growth. This effect of social interactions within a group on growth and height of their members has been described by Aßmann and Hermanussen (2013), Hermanussen and Scheffler (2019) and appears to also apply for young adult Vietnamese migrants who grew up in Germany (Table 1). Young Vietnamese migrants are taller than their cousins who stayed in Vietnam. This was also described for Maya migrants in the U.S. (Bogin et al. 2018), Japanese migrants in the U.S (Boas 1912), and Turkish migrants in Germany (Özer and Scheffler 2018).

Body height of migrants reflects the degree of integration. Height of Turkish migrants in Germany is negatively related to their sense of belonging to the Turkish culture in Germany. Similar to Vietnamese migrants (Figure 2a) the Turkish migrants showed a positive association of body height to height of the best friends (Özer and Scheffler 2018). The endocrine regulation of this mechanism is still unknown.

In our study, we found no direct impact of the degree of cultural identification of Vietnamese people who grew up in Germany on the regulation of body height (Figure 1). But according to the cultural background, Vietnamese migrants seem to have the ability to adapt to given situations and they appear willing to leave the past behind and look ahead (Stephan 2000). Adaptation is part of Vietnamese culture. In line with a centuries-old Vietnamese tradition, high education is considered the prerequisite for social advancement (Stephan 2000). Education and social advancement are important also in the host community. Our study population went to school for on average 12.65 years $(\mathrm{SD}=1.04)$ and underwent an additional educational training for another 3.04 years. $(\mathrm{SD}=1.65)$. On average the educational degree of Vietnamese graduates is higher than that of other migrant groups in Germany (Statistisches Bundesamt 2019). Due to their traditional values, 13-year-old Vietnamese adolescents anticipate future social advancements also in their host population and accordingly try to adjust strategically also in growth and final height as reflected by the strong association between height expectation at age of 13 years and attained height as adults (Figure 2b).

Receiving higher social position is accompanied by social competition. Social com- 
petition is reflected in growth. The anticipated future position of an individual in society fuels developmental strategies and is finally mirrored by adolescent growth and adult body height. Strategic growth adjustments occur during adolescence (Hermanussen and Scheffler 2016). Adolescents anticipate their future position and adjust growth accordingly as we observed in the female and particularly in the male Vietnamese migrants.

Boys are more sensitive to environmental stressors and stimuli than girls (Hasibuan et al. 2020). This is in line with the greater trend in male height with $7.44 \mathrm{~cm}$ compared with that of the females $(3.85 \mathrm{~cm})$ observed in this study. It may be speculated that the lower secular trend among women also results from traditional behavioral patterns, in that particularly the women in Asian cultures tend to be less open to new ideas and experiences.

A limitation of this study is that it is retrospective. It is unclear to what extent a personal height expectation at age 13 years is correctly remembered at later age, and whether current body height might shape past memories of height expectations.

\section{Conclusion}

Vietnamese migrants in Germany adjust in body height towards height of their peers as generally seen in migrants and reflecting competitive growth and strategic growth adjustments. Growth adjustments reflect the emotional challenge during the process of integration towards future social position within the host society.

The magnitude of this intergenerational secular trend supports the concept that human growth depends on SEPE factors (Bogin 2021a; 2021b).

\section{References}

Aßmann, C.; Hermanussen, M. (2013): Modeling determinants of growth: evidence for a community-based target in height? In Pediatric Research 74 (1), pp. 88-95. DOI: 10.1038/pr.2013.50.

Boas, F. (1912): Changes in bodily form of descendants of immigrants. In American Anthropol 14, pp. 530-562.

Bogin, B. (2021a): Patterns of human growth: Cambridge University Press.

Bogin, B. (2021b): Social-Economic-Political-Emotional (SEPE) factors regulate human growth. In Human Biology and Public Health 1. DOI: 10.52905/hbph.v1.10.

Bogin, B.; Hermanussen, M.; Scheffler, C. (2018): As tall as my peers - similarity in body height between migrants and hosts. In Anthropologischer Anzeiger74 (5), pp. 363-374. DOI: 10.1127/anthranz/2018/0828.

Bogin, B.; Loucky, J. (1997): Plasticity, political economy, and physical growth status of Guatemala Maya children living in the United States. In American Journal of Physical Anthropology 102 (1), pp. 17-32. DOI: 10.1002/ (SICI)1096-8644(199701)102:1<17::AID-AJPA3 > 3.0.CO; 2-A.

Bogin, B.; Smith, P.; Orden, A. B.; Varela Silva, M. I.; Loucky, J. (2002): Rapid change in height and body proportions of Maya American children. In American Journal of Human Biology: The Official Journal of the Human Biology Council 14 (6), pp. 753-761. DOI: 10.1002/ajhb.10092.

Esser, H. (2016): Sprache und Integration: Konzueptionelle Grundlagen und empirische Zusammenhänge: KMI Working Paper Series, Working Paper Nr. 7. In Östereichische Akademie der Wissenschaften, pp. 1-23.

Groth, D.; Scheffler, C.; Hermanussen, M. (2019): Body height in stunted Indonesian children depends directly on parental education and not via a nutrition mediated pathway - Evidence from tracing association chains by St. Nicolas House Analysis. In Anthropologischer Anzeiger. DOI: 10.1127/anthranz/2019/1027.

Growth reference data for 5-19 years (2021). Available online at https://www.who.int/tools/growth-referencedata-for-5to19-years, checked on 1/22/2021.

Hasibuan, S. N.; Pulungan, A.; Scheffler, C.; Groth, D.; Hermanussen, M. (2020): Environmental stimulation on height: The story from Indonesia. In Anthropologischer Anzeiger77 (5), pp. 423-429. DOI: 10.1127/anthranz/2020/1209.

Hermanussen, M.; Aßmann, C.; Groth, D. (2021): Chain reversion for detecting associations in Interacting variables -St. Nicolas House analysis. In International Journal of Environmental Research and Public Health 18 (4), p. 1741. DOI: 10.3390/ijerph18041741. 
Hermanussen, M.; Scheffler, C. (2016): Stature signals status: The association of stature, status and perceived dominance - a thought experiment. In Anthropologischer Anzeiger73 (4), pp. 265-274. DOI: 10.1127/anthranz/2016/0698.

Hermanussen, M.; Scheffler, C. (2019): Body height as a social signal Papers on Anthropology. In Papers on Anthropology XXVIII, 2019, pp. 47-60.

LamaPoll: Sichere Online Umfrage \& Fragebogen erstellen | Umfrage Tool kostenlos testen (2021). Available online at https://www.lamapoll.de/ ?gclid=Cj0KCQiA4feBBhC9ARIsABp_nbWsgR0rPgjy1v6HZiB1J9Xy1IjdysM1Q1G4gtxvdx5W2TO7NAU GqAaAj9mEALw_wcB, checked on 3/2/2021.

Landis, D.; Alber, R. D. (Eds.) (2012): Handbook of ethnic conflict: international perspectives. - International and cultural psychology: Springer, New York.

Laor, A.; Seidman, D. S.; Danon, Y. L. (1991): Changes in body height among selected ethnic groups. In Journal of Epidemiology and Community Health 45 (2), pp. 169-170. DOI: $10.1136 /$ jech.45.2.169.

Marouli, E.; Graff, M.; Medina-Gomez, C.; Lo, K. S.; Wood, A. R.; Kjaer, T. R. et al. (2017): Rare and low-frequency coding variants alter human adult height. In $\mathrm{Na}$ ture 542 (7640), pp. 186-190. DOI: 10.1038/nature21039.

Marsh, Abigail A.; Yu, Henry H.; Schechter, Julia C.; Blair, R. J. R. (2009): Larger than life: humans' nonverbal status cues alter perceived size. In PloS One 4 (5), e5707. DOI: 10.1371/journal.pone.0005707.

Mascie-Taylor, C. G. N.; Krzyżanowska, M. (2017): Biological aspects of human migration and mobility. In Annals of Human Biology 44 (5), pp. 427-440. DOI: 10.1080/03014460.2017.1313448.
NCD Risk Factor Collaboration (2016): A century of trends in adult human height. In eLife 5. DOI: 10.7554/eLife.13410.

Özer, A.; Scheffler, C. (2018): Affinity to host population stimulates physical growth in adult offspring of Turkish migrants in Germany. In Anthropologischer Anzeiger74 (5), pp. 359-364. DOI: 10.1127/anthranz/2018/0825.

R Core Team (2018): R: A language and environment for statistical. Vienna, Austria. Available online at URL https://www.R-project.org/.

Robert-Koch-Institut (2021): KiGGS - Studie zur Gesundheit von Kindern und Jugendlichen in Deutschland: Home. Available online at https://www.kiggsstudie.de/deutsch/home.html, checked on 1/22/2021.

Statista (2021): Ausländer in Deutschland bis 2019: Herkunftsland | Statista. Available online at https://de.statista.com/statistik/daten/studie/1221/ umfrage/anzahl-der-auslaender-in-deutschland-nachherkunftsland/, checked on 1/22/2021.

Statistisches Bundesamt (2019): Absolventen/Abgänger nach Abschlussart und Geschlecht, checked on $1 / 29 / 2021$.

Stephan, U. (2000): Einstellungen und Erwartungen vietnamesischer Jugendlicher an Dien Hong, einen deutsch-vietnamesischen Verein in Rostock und seinen Jugendtreff: Magisterarbeit. Rostock.

Tyrrell, J.; Jones, S. E.; Beaumont, R.; Astley, C. M.; Lovell, R.; Yaghootkar, H. et al. (2016): Height, body mass index, and socioeconomic status: mendelian randomisation study in UK Biobank. In BMJ 352, i582. DOI: 10.1136/bmj.i582. 